\title{
Method for evaluating the snagging propensity of roofing membranes in buildings by roosting bats
}

Article

Accepted Version

Essah, E. A., Russell, S. J., Waring, S. D., Fergusonc, J., Williams, C., Walsh, K., Dyer, S. and Raynor, R. (2020) Method for evaluating the snagging propensity of roofing membranes in buildings by roosting bats. Building Research \& Information, 48 (8). pp. 886-898. ISSN 1466-4321 doi:

https://doi.org/10.1080/09613218.2020.1763773 Available at https://centaur.reading.ac.uk/90562/

It is advisable to refer to the publisher's version if you intend to cite from the work. See Guidance on citing.

To link to this article DOI: http://dx.doi.org/10.1080/09613218.2020.1763773

Publisher: Taylor \& Francis

All outputs in CentAUR are protected by Intellectual Property Rights law, including copyright law. Copyright and IPR is retained by the creators or other copyright holders. Terms and conditions for use of this material are defined in the End User Agreement. 


\section{CentAUR}

Central Archive at the University of Reading

Reading's research outputs online 


\title{
Method for evaluating the snagging propensity of roofing membranes in buildings by roosting bats
}

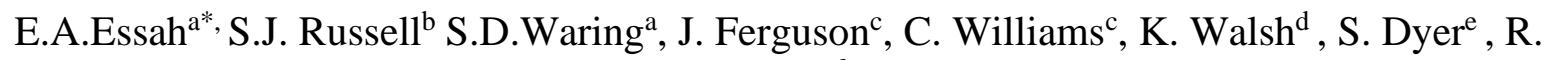 \\ Raynor $^{\mathrm{f}}$
}

\author{
${ }^{a}$ School of the Built Environment, University of Reading, Reading, UK \\ ${ }^{b}$ School of Design, University of Leeds, Leeds, UK \\ ${ }^{c}$ Bat Conservation Trust, London, UK \\ ${ }^{d}$ Natural England, Crewe, UK \\ ${ }^{e}$ Natural Resources Wales, Bangor, UK \\ ${ }^{f}$ Scottish Natural Heritage, Inverness, UK
}

*corresponding author: e.a.essah@reading.ac.uk

\begin{abstract}
Many buildings suitable as bat roosts contain synthetic roofing materials, hereafter referred to as Non-Bitumen Coated Roofing Membranes (NBCRMs) - this includes Breathable Roofing Membranes (BRMs) and non-Permeable Roofing Membranes (nPRMs), rather than $1 \mathrm{~F}$ felts. Building regulations require all construction materials to be fit for purpose, but some BRMs (although appropriate for their intended purpose) can potentially threaten the viability of existing, legally protected roosts because of the way bats physically interact with their surface. With the assistance of the Isle of Wight Bat Hospital and real-world observations of how bats physically interact with NBCRMs within a roof void, we present a new laboratory test method capable of reproducing the progressive disintegration of NBCRM surfaces due to the plucking effect of bat claws. The resistance to NBCRM disintegration was characterised using a modified laboratory fabric pilling box test method. The method reproduced the 'fluffing' effects and projections of loops of filaments on the surface of BRMs that have been observed within bat roosts. It was established that spunbond nonwoven BRMs, can be highly susceptible to surface disintegration. The newly developed method is intended to aid selection of NBCRMs that reduce the risk to bats in their roosts, promoting bat conservation.
\end{abstract}

Key words: Roofing membranes, Bats, Pipistrelle, Serotine, Nonwoven 


\section{Introduction}

This paper investigates the interaction between Non-Bitumen Coated Roofing Membranes (NBCRMs) and bats. In recent decades the emergence of nonwoven roofing membranes has seen these products being much more widely used in place of traditional bitumen felt. Bats in the UK consist of 17 breeding species with many of these using buildings as places of shelter in which to roost (Stebbings, 1988). This has been the situation for as long as the natural roosting opportunities have been lost and people have been using buildings. All bats and their roosts are protected by law. The increasing use of NBCRMs has brought the use of roofs by bats (whether using the internal roof space or the gap between the membrane and roof tiles) into direct contact with these membranes and the result has been membranes that become loosened in their structural integrity as the result of the action of bats claws. These loosened loops of material have led to bats becoming entangled and trapped resulting in their death. In loosening the fibres of the material, the membrane's function is also compromised. The solution to this situation is much sought after by statutory nature conservation organisations, the construction sector and bat conservationists. This paper provides, for the first time, a methodology for testing any NBCRMs for their tendency to lose structural integrity in this way thereby allowing solutions to be effectively sought.

Generally, the role and design of buildings has always been to provide protection from the wind, sun, cold, rain and other environmental conditions, which have evolved over many years (Santamouris, 1998). In the past, building designs were simple and considered these environmental conditions. However, at the end of the $19^{\text {th }}$ century, building construction was modified with increasing complexity and size, to suit growing technological advancement and the change in climate (Loomans, 1988). At present, in the United Kingdom (UK) the most common type of domestic roof construction used is pitched roofs. By design and construction, pitched roofs include a system of structural elements usually made from timber which provide support to an impermeable or breathable underlay. Over the underlay, tiling battens are nailed directly to the structural elements, providing support and a fixing point for a slate, concrete or clay tiles creating spaces between battens and membranes.

Eighty percent of domestic roofs in the UK, have insulation on the horizontal ceiling with an accessible, cold loft space above, designed for allowing ventilation through the eaves driving out transported moisture generated from the dwellings below into the roof space. There are however many opportunities to build-in spaces for biodiversity (including roof spaces) whilst 
still complying with all the necessary regulations for a building, including for low and zerocarbon buildings (Williams et al., 2013) and whilst this paper is predominantly about the legal protection of existing bat roosts, the use of a suitable materials will enable new roosts to establish as the hoped-for recovery of our severely depleted bat populations start to take effect. The most important facet of the roof being considered in this research is the function of the underlay most of which are non-woven materials. It must however be noted that buildings in the UK continue to evolve through several changes in roof design and practice. These, together with changes in building regulations, social factors and the significance of biodiversity in the built environment, have caused several influences on the performance of buildings. Several of these changes have been documented by Sanders (2002) but it is the introduction and vigorous marketing of vapour permeable under tiling membranes, as an alternative to loft space ventilation, with insulation laid on the horizontal ceiling that is of direct relevance to this paper (Sanders, 2002).

Principally, there are two types of roofing underlay: vapour permeable and vapour impermeable, both of which are defined in British Standards BS5250:2011 (BSI, 2011) and BS 5534:2003 (BSI, 2003). Impermeable membranes have a water vapour resistance level of > 0.25 MNs/g (Stirling, 2009). They have very low permeability in both directions and can therefore give rise to moisture trapped within the roof void. In this case, additional ventilation in the roof space is essential (Goss, 2007). Traditional bitumen felt (BSI, 747:2000a) is an example of an impermeable underlay. On the other hand, permeable membranes have a water vapour resistance value of $<0.25 \mathrm{MNs} / \mathrm{g}$ with the capability to allow water vapour, rising into the roof space, to escape through the underlay. This reduces the risk of condensation, whilst preventing rain penetration through the roof covering into the building (Goss, 2007). Herein, these permeable membranes are referred to as Breathable Roofing Membranes (BRMs). In addition, to BRMs there are also non-permeable membranes (nPRM) that are used in buildings. For the purpose of this paper where non-permeable and breathable roofing membranes are collectively considered, the term Non-Bitumen Coated Roofing Membrane (NBCRM) is used.

The BRM structure allows diffusion of water vapour through the inner to the outside surface without allowing liquid ingress into the roof space. BRMs are commonly constructed from spunbond polypropylene (SBPP) or spunbond polypropylene (PP)/polyethylene nonwoven fabrics, laminated either side of a functional vapour permeable layer such as a membrane, film, meltblown or flashspun fabric (Albrecht, 2003). The difference between products often relates 
to the method used to create the functional layer that allows the membrane to breathe (DuPont, 2011; Waring et al., 2013). A nonwoven is defined by EDANA as 'a sheet of fibres, continuous filaments, or chopped yarns of any nature or origin, that have been formed into a web by any means, and bonded together by any means, with the exception of weaving or knitting.' Spunbond fabrics used in BRMs are thermal bonded nonwovens made of randomly oriented continuous filaments (EDANA, 2017; Wilson, 2007; Bhat 2007).

Figures 1 and 2 show Scanning Electron Microscope (SEM) images of two examples of nonwoven BRM. One has undergone thermal point bonding (Figure 1) and the other has more extensive thermal bonding (Figure 2). By contrast, Figure 3 shows a woven underlay made of fibreglass.
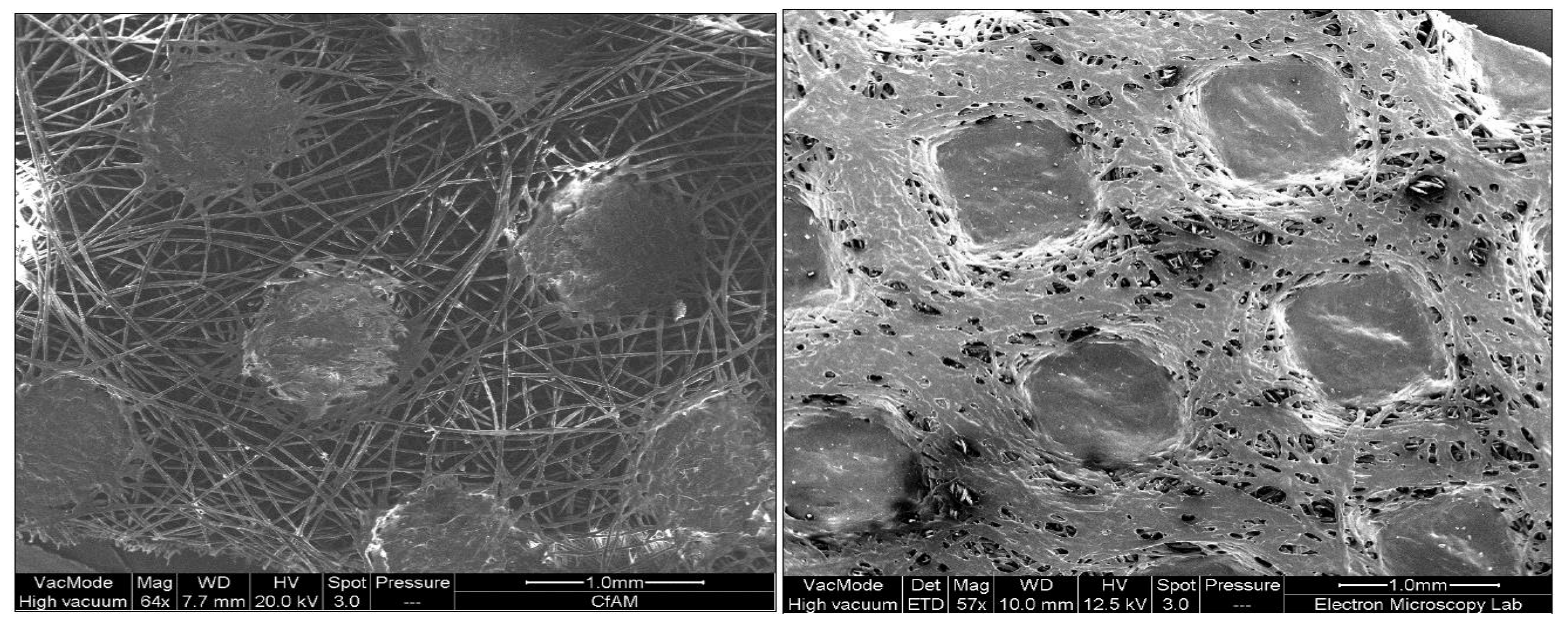

Figure 1. Surface of a thermal bonded PP Figure 2. Surface layer of a thermal bonded PP spunbond fabric in a BRM (64x magnification). spunbond fabric in a BRM (57x magnification).

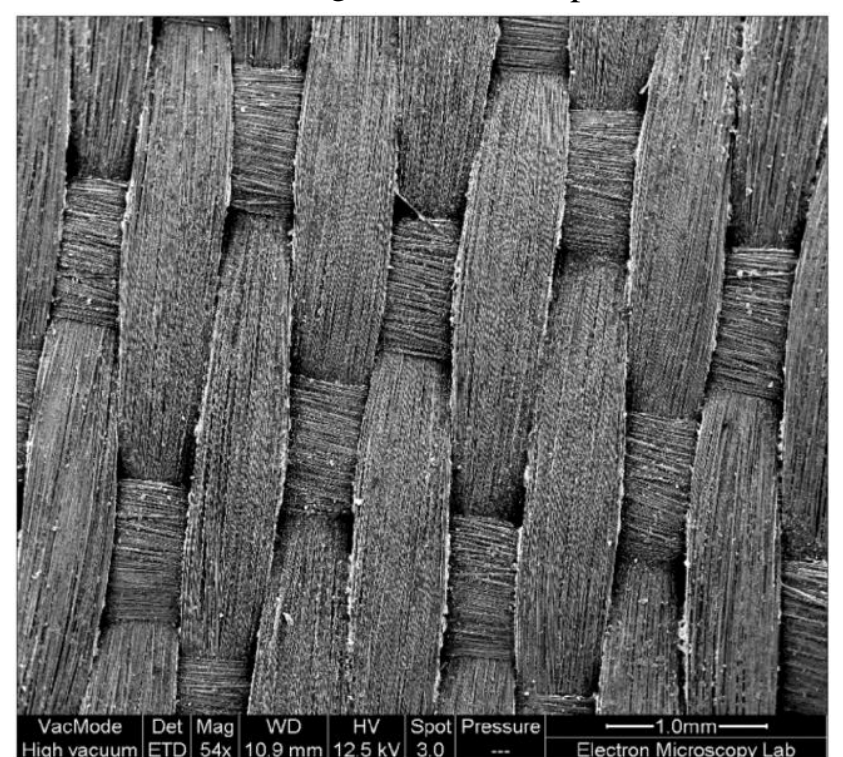

Figure 3. Image of a woven fiberglass fabric, surface coated with aluminum (54x magnification), (Specimen D in Table 1) 
All 17 British bat species that breed here make use of buildings on occasion (Stebbings, 1988) and for a significant number of species, buildings are essential as their roost sites (Dietz et al., 2009; Hutson, 1993). Bats will roost in a range of building types such as dwellings, churches (Marnell \& Presetnik, 2010) and barns (Briggs, 2004). In addition, bats will make use of a wide range and age of buildings depending on roosting features, habitat and potential threats present; though more species and greater numbers have been recorded in older buildings (Briggs, 2004; Simon et al., 2004; Williams, 2010).

All species of bat, their breeding sites and resting places (roosts) are protected in the UK. In England and Wales under the Wildlife and Countryside Act 1981 (as amended) ('the W\&CA 1981') and the Conservation of Habitats and Species Regulations (2017) ( 'the Habitats Regulations') and in Scotland by the Conservation (Natural Habitats, \& c.) Regulations 1994 (as amended). Bats and their roosts are protected by law due to serious declines in numbers over the past century; predominantly due to loss of suitable roost sites and feeding habitats (Entwistle et al, 1997) or disturbance and change of use of man-made roosts (including buildings) (Kunz and Reynolds, 2003). Roosts are protected even when bats are not present. As many bats rely on buildings and specifically roofs for roosting, this makes them vulnerable to changes in building materials (Waring, 2014). The roosts discussed in this research refers to roof spaces with breathable membranes installed for moisture transport phenomena.

During roosting, bats physically interact with the surface of roofing membranes through the gaps between battens and in the roof space (Figure 4). Their claws snag the surface of the NBCRM, which can cause loops of continuous filaments to be teased free from the fabric structure to produce surface 'fluffiness'. Concerns have been raised since 2004 about the level of bat mortality (Waring et al, 2013; Waring, 2014) as they are often caught in these loose, strong filaments, becoming fatally entangled. In Scotland this situation would not normally arise in the roof void as the membrane would be located behind the wooden sarking boards, against which the bats would roost. However, there is still potential for crevice dwelling bats such as Pipistrelle species to interact with the NBCRMs when roosting underneath roof tiles.

In carrying out works on buildings that include re-roofing, the legal protection of bats can come into conflict with the use of NBCRMs where the death of bats (as a protected species) occurs due to entanglement with these materials. Within the process of operations that include re- 
roofing, if a bat roost is known or found, an ecologist will provide advice to the building professionals. It is the ecologist who will be mindful of the risks of NBCRMs and the advice of the statutory nature conservation bodies to use type $1 \mathrm{~F}$ bitumen roofing felt with a hessian matrix instead.

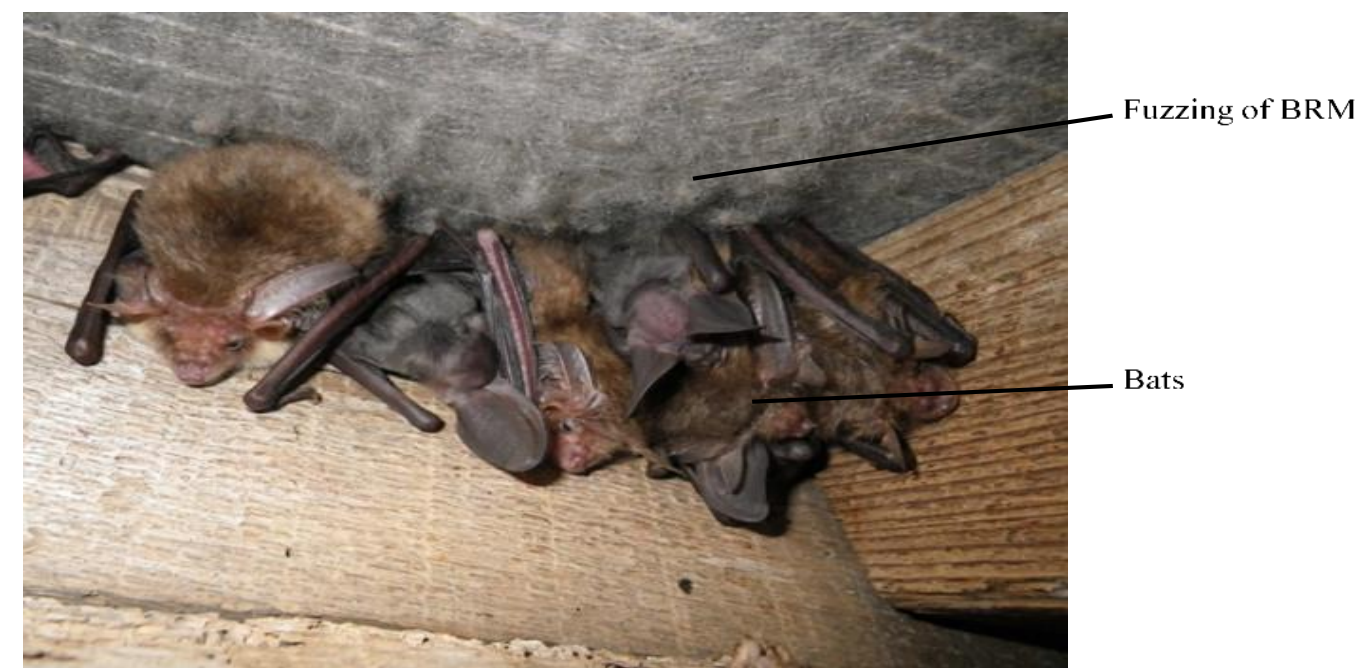

Figure 4. Example of fuzzing on a nonwoven membrane within a bat colony (Courtesy of John Martin, Cumbria, UK)

The fuzzing, pilling and snagging propensity of fabrics can be tested in the laboratory (Waring, 2014). Fuzzing as described in BS 5811 (BSI, 1986) is 'the roughing up' of the surface fibres and/or teasing out the fibres from the fabric, which produces a change in appearance. This is normally due to abrasion. Snags also form undesirable loops on the surface of fabrics (BS 8479) due to yarns or filaments being pulled after catching on a solid or sharp object. Segments of filaments pulled loose from the surface first form loops, which over time begin to entwine with other loops to create a 'fluffy' appearance. Pilling is the entangling of loose fibres or filaments into balls (pills) visible on the fabric surface (BS 5811, 1986) due to further abrasion.

Owing to the following knowledge gaps, it has not been possible for the statutory agencies, which advise on such matters, to recommend for use any currently available NBCRM and hence, still advise the use of traditional bituminous felt in roosts (Waring and Essah 2016):

a) There is no standard method of evaluating the surface integrity of roofing membranes that enables snagging resistance by bats to be assessed.

b) No specification testing is conducted to determine whether membranes (NBCRMs) fall within the limits allowed to greatly increase bat safety.

c) There is no clear understanding of what constitutes a product that would avoid bat entanglement without compromising the moisture transport properties of BRMs. 
This matter is of wider importance than the UK and is a topic discussed at EUROBATS (https://www.eurobats.org/), which is an Agreement on the Conservation of Populations of European Bats that came into force in 1994 and has 37 range states acceded to the Agreement. The Agreement provides a framework of co-operation for the conservation of bats throughout Europe, Northern Africa and the Middle East. This aims of this research have been presented at EUROBATS meetings and the resultant paper is keenly awaited. The purpose of this work is to establish a test method that can be applied to any NBCRM for characterising the resistance to surface disintegration and loop formation of due to the plucking action of bat claws thereby identifying a wider range of materials beyond the traditional bitumen based products that are acceptable for use in bat roosts.

\section{Experimental Set-up}

\section{Materials}

For the purpose of this research, four samples of NBCRMs of varying construction were obtained from industry suppliers in the UK. The industrial products (specimens A, B, C) comprised bi- and tri-layer composite nonwovens in which one or more spunbond (S) layers is combined with a vapour permeable and liquid resistant layer with a smaller mean pore size. This 'functional' layer consisted of either a meltblown (M) or flashspun (FS) nonwoven, a microporous film (MPF), or monolithic hydrophilic film (MOF), (Table 1). Notably, specimens $\mathrm{A}, \mathrm{B}$ and $\mathrm{C}$ are BRMs and Sample D is a woven nPRM which has a fire-retardant aluminium polymer coating on its surface. These four membranes were representative of the four main manufacturing processes available. There is a much bigger number of branded membranes on the market, but they largely fall within these four representative types.

Table 1 Specification and characteristics of roofing membranes

\begin{tabular}{|c|c|c|c|c|}
\hline Specimens & A & B & C & D \\
\hline Number of Layers & 3 & 3 & 2 & N/A \\
\hline Construction & S-MPF-S & S-M-S & S-FS & N/A \\
\hline Functional Layer & MPF & M & FS & N/A \\
\hline Fabric weight $\left(\mathbf{g ~ m}^{-2}\right)$ & 130 & 148 & 175 & 450 \\
\hline Thickness (m) & 0.00050 & 0.00043 & 0.00067 & 0.00033 \\
\hline Vapour Resistance (MNs/g) & 0.19 & 0.08 & 0.09 & 0.55 \\
\hline
\end{tabular}

(Source: Waring 2014) 


\section{Snagging Propensity Test Methodology}

In bat roosts, the claws play a major role in enabling bats to hold on to and reposition themselves on to the roofing membrane. As the claws are lifted, snagged filaments are plucked from the surface, which after a period or repeated interaction produces a 'fuzzy' or partially delaminated surface. Two British Standard tests that reflect similar damage mechanisms are already used within the textile industry although they are not routinely used to assess roofing membrane fabrics.

- BS 8479 - Method for determination of propensity of fabrics to snagging - rotating chamber method (BSI, 2008)

- BS EN ISO 12945-1 - Determination of propensity to surface fuzzing and pilling - Part 1: pilling box method (BSI, 2001).

To meet the requirements of an experiment designed to replicate the mechanism of interaction between a bat and a roofing membrane, both aforementioned British Standards were used as the foundation for development of a new test method. Modifications made to these existing methods are described herein.

The Rotating Chamber Pilling Box or Snag Tester: A rotating chamber or pilling box, as described in BS EN ISO 12945-1 (BSI, 2001) consists of a cubical box (Figure 5) with internal dimensions of $235 \mathrm{~mm}$ and $229 \mathrm{~mm}$ (length by width). All the internal surface of the box is normally lined with an abradant of $3 \mathrm{~mm}$ thick cork to allow the box to be easily cleaned. To simulate the plucking mechanism produced by bat claws, an alternative abradant was required that, when rubbed against the surface of the NBCRM, would be capable of attaching and potentially dislodging loosely bonded filaments. Real bat claws were dismissed due to the impracticality of obtaining and fitting them reproducibly, their brittleness and the implications in terms of modifying the pilling box. 


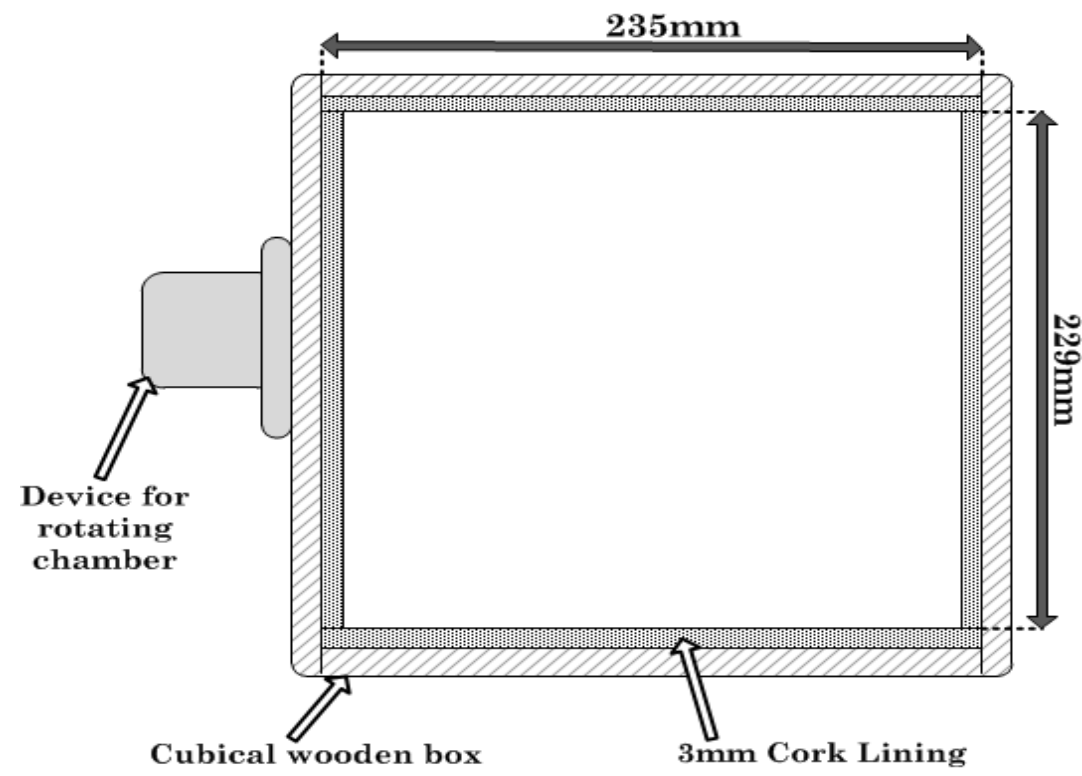

Figure 5. Sectional diagram of the rotating chamber pilling box used for the entanglement test

Therefore, for practical reasons, a reproducible synthetic material that has the advantage of being robust, reproducibly manufactured and readily applied by multiple laboratories was used. One side of Velcro® consists of a woven base fabric from which small filamentous hooks project. It was observed that the projecting hooks of the Velcro® structure (Figure 6) crudely mimic a bat claw in terms of curvature and stiffness. Initial evaluations with fine pins and needles were also made, but none mimicked the claw action as well as the Velcro®. Although this might be a potential limitation regarding how accurately the bat claw was mimicked, use of the natural material was impossible as it would have required the killing of a number of bats which are a protected species. The use of Velcro however, provided significant accuracy within limits to the nature and movement of the bat claw.

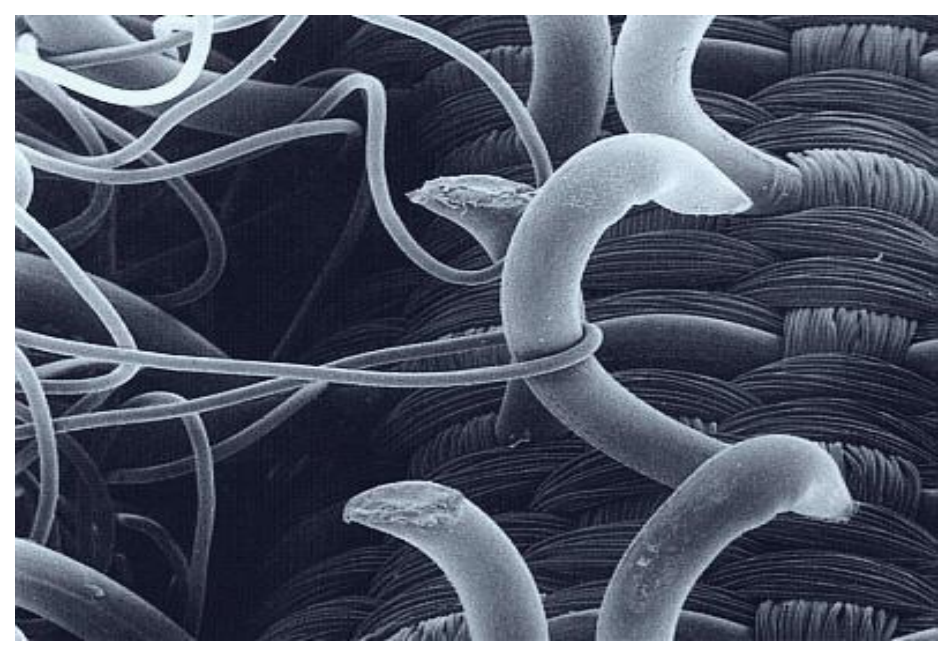

Figure 6. SEM image (x35 magnification) of standard Velcro® showing the projecting hooks attaching to adjacent filament loops (Images taken by the Boston Museum of Science, 2012) 
Adhesive strips of the Velcro® hooks were prepared of dimensions $25 \mathrm{~mm}$ (w) x $229 \mathrm{~mm}$ (l). Three were then applied in the same geometric arrangement to each internal surface of the pilling box as illustrated in Figure 7. The direction of the Velcro® strips was rotated through $90^{\circ}$ on adjacent surfaces, so in total three different directionalities were available. This ensured surface filaments would be brought in to contact at various directions and angles, as would occur in a bat roost. Once the Velcro® strips were affixed they were trimmed using a sharp blade to create a uniform fit within the pilling box.

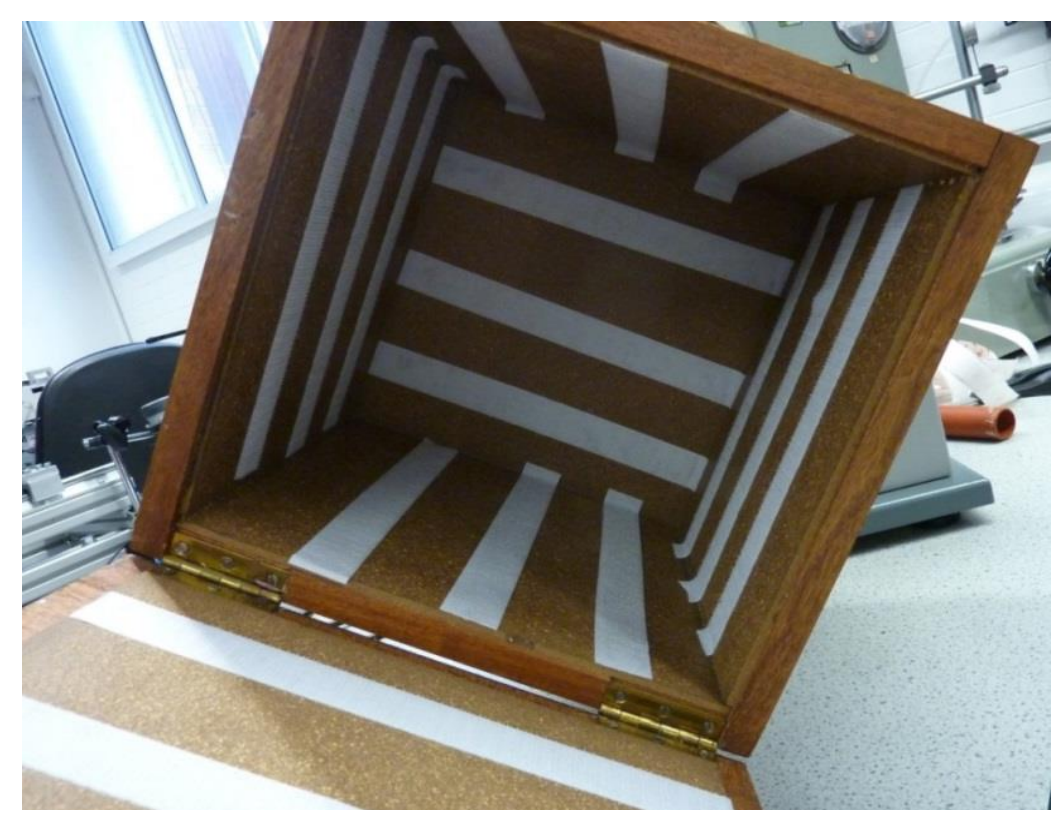

Figure 7. Interior of the pilling box, showing the Velcro® strips attached to the cork lined interior before trimming

Specimen Tubes: The specimen tubes used were as described in BS EN ISO 12945-1 (BSI, 2001). They consist of a hollow polyurethane tube with an outside diameter of $31.5 \mathrm{~mm}, 140$ $\mathrm{mm}$ long, thickness of $3.2 \mathrm{~mm}$ and a mass of $52 \mathrm{~g}$. Notably, this is around $15 \mathrm{~g}$ greater than the average weight of the largest UK bat species. However, lighter sample holders did not accelerate surface abrasion of specimens. Whilst there are no data on the pull-out forces generated by a bat claw as the leg is lifted, it is likely as with many mammals that the force generated is substantially greater than the body weight. Hence the specimen tube was considered the most viable testing option.

Sample Directionality: In both BS EN ISO 12945-1 (BSI, 2001) and BS8479 (BSI, 2008) the method states that any test specimen should contain two samples of each specimen placed on 
the tube in the machine direction and two in the cross-machine direction. However, due to the random orientation of the filaments in the NBCRM surfaces and the alternating orientation of the Velcro® strips, this was considered unnecessary. Therefore, for each sample, three tubes were employed, and reducing the number of tubes also decreased the probability of unwanted tube-to-tube contact during testing.

Attachment of Samples to Specimen Tubes: The method described in BS 8479 (BSI, 2008) and BS EN ISO 12945-1 (BSI, 2001) for attaching a test sample to the polyurethane tube requires that the material be sewn, to form a cylinder that is then placed over the tube. The stiffness of the NBCRMs means this procedure would create a protruding area; distorting the membrane and affecting the area of the NBCRM in contact with the pilling box, during testing. For this reason, double-sided adhesive tape was used to attach the NBCRM sample to the tube. Prior to testing, both the polyurethane tubes and NBCRM test samples were conditioned in a standard atmosphere in accordance with BS EN ISO 139:2005+A1 (BSI, 2011b) for $24 \mathrm{~h}$.

Samples of the same NBCRM to be tested were affixed to the three specimen tubes. This was achieved by positioning three pieces of double-sided adhesive tape (100 $\mathrm{mm}$ long) evenly along the length of the tube, ensuring the outer edges of the tape were roughly $10 \mathrm{~mm}$ from the end of the tube (Figure 8). The membrane (i.e. NBCRM) specimen was then attached by placing the specimen tube on top of the sample and firmly rolling the tube, until the NBCRM was fixed in place ensuring no air-gap between the sample and the tube. The sample edges were then checked to ensure they were lying flat against the surface of the tube. This was essential as any edges that were not securely fastened could cause the sample to detach from the tube during testing.

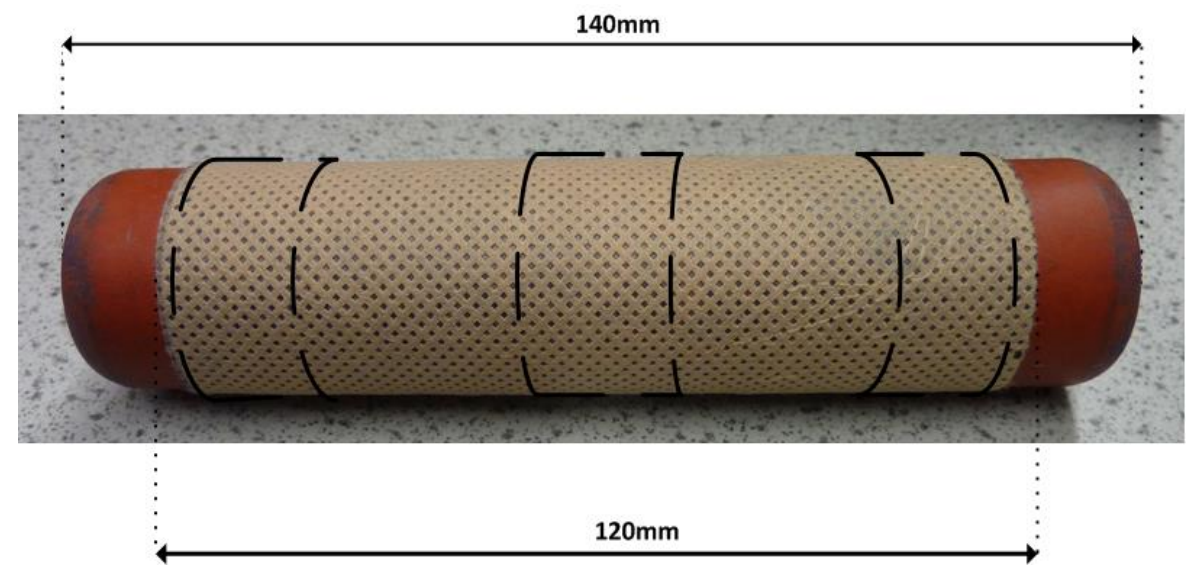

Figure 8. Image showing where the NBCRM sample strips are attached to a polyurethane specimen tube with lines indicating the position of underlying adhesive tape 
For each sample (A, B, C, D listed in Table 1), three specimens of each were mounted on three separate tubes (i.e. 9 specimens of each sample) and placed into the pilling box test chamber (Figure 7) and the hinged door securely closed. The chamber which was integrated with a rotation controller was then set to rotate at $60 \mathrm{r} \mathrm{min}^{-1}$ and run for a predetermined number of rotations: $n=50,100,250,500,1000,1500,2000,3000$ or 5000. All samples were tested at all predetermined rotation intervals up to $n=1000$. Only NBCRM samples free of loop formation on the surface after $n=1000$ rotations were tested beyond the set target of rotations. Three control samples (rotations $n=0$ ) were also retained for evaluation. After each set of rotations, the tubes were taken from the pilling box, inspected and the loops formed were counted.

Optical microscopy and determination of snagging propensity: The number of dislodged filament loops per unit area (loops $\mathrm{cm}^{-2}$ ) on both sides of each specimen was measured by means of optical microscopy (40x magnification). This involved using a card template (100 $\mathrm{mm} \times 100 \mathrm{~mm}$ ) cut out with 10x 1 $\mathrm{cm}^{2}$ square apertures (Figure 9).

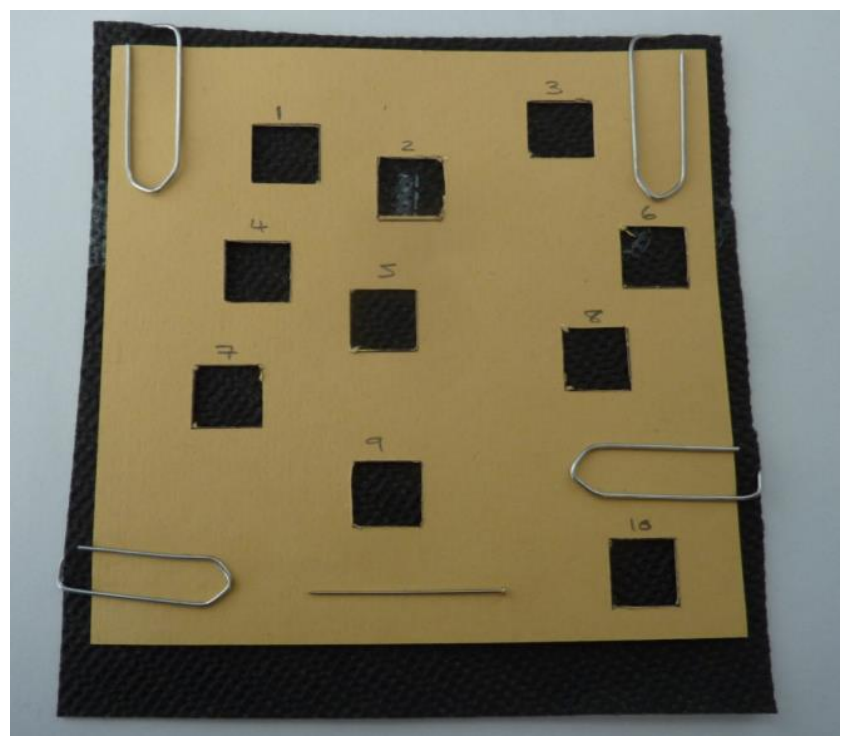

Figure 9. Photograph of the card grid with $10 \times 1 \mathrm{~cm}^{2}$ used for loop counting on test specimens

The template was then secured over the centre of the test specimen and viewed under a white LED incident light source. The numbers of loops in each square were counted by scanning the sample from left to right. Loops were only considered if they were projecting from the NBCRM surface and had clearly been pulled free from the structure. The cut off value was defined as an average number of loops $\geq 1 \mathrm{~cm}^{-2}$. This threshold was chosen as surface loops of filament 
are directly implicated with bat entanglement, so their presence on the NBCRM surface is the key criterion.

\section{Verification of experimental method}

A small field study was conducted to verify susceptibility to disintegration and loop formation of three different BRM samples (sample A-C) and one nPRM (sample D) when bats crawl across their surface within a roost. These observations were then compared with the corresponding laboratory pilling box, test data. A sample of each NBCRM specimen $(300 \mathrm{~mm}$ x 900mm) was fitted into an aviary at the Isle of Wight bat hospital (Figure 10). Two aviaries were chosen because they contained bat species; pipistrelles and serotines, which have been previously reported to have been found entangled in BRMs installed in real buildings. The four specimens A, B, C, and D (see Table 1) were fitted into the aviaries (Figure 10). An aviary (flight cage) at a bat hospital was chosen as this enabled ground truthing of the interaction of bats with the membrane but within a controlled environment in which the bats were under observation to prevent any risk of injury or death as a result of entanglement. This approach would have not been possible in a roof-void roost and was therefore discounted as unethical. This is acknowledged as a limitation of this approach although the bat hospital proved a valid proxy. In addition, the fact that only the front surface (i.e. where bats mostly roost) of the NBCRM was considered maybe a limitation since bats can be found to also roost between the tiles and the battens (i.e. the back surface of the material). 


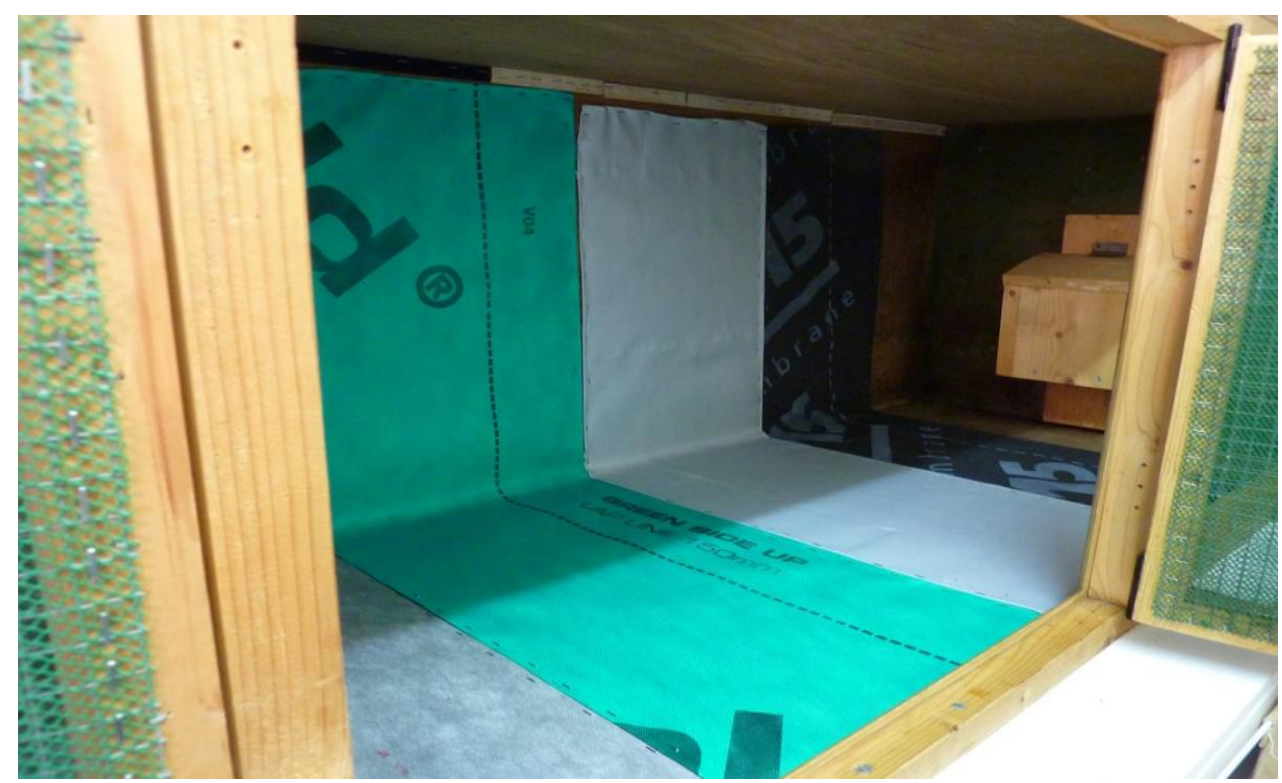

Figure 10. Photograph showing the four test specimens fitted inside the pipistrelle aviary

Prior to fitting of the membranes, the bats were removed, and the aviaries cleaned thoroughly. After four months exposure of the NBCRMs in the aviary, the samples were removed and returned to the lab for microscopic analysis of filament loop projection in the same manner as the pilling box tested samples.

\section{Results and Discussion}

The mean number of loops per square centimetre $\left(\mathrm{cm}^{-2}\right)$ measured on the front $(\boldsymbol{f})$ and back $(\boldsymbol{b})$ surfaces of each NBCRM (samples A, B, C and D) following the modified pilling box test is given in Table 2. For the three nonwoven BRMs and one nPRM tested, the mean number of loops increased with increasing mechanical abrasion (number of rotations). By contrast D sample exhibited no loop formation up $n=1000$ rotations. This suggests the spunbond fabric surfaces are more susceptible to dislodgement of individual or groups of filaments than the woven sample due to the ability of the tips of the Velcro® abradant to catch and dislodge filament segments between thermal bond points. Owing to the layered planar structure of thermal bonded spunbond nonwovens and spatially distributed bond points, it is possible for individual or small groups of continuous filaments to be plucked out from the base structure, forming projecting loops on the BRM's surface. Area bonding wherein heat is applied uniformly across the fabric surface to partially melt the filaments together, application of adhesives or film coatings to the surface may be potential routes for reducing the propensity for BRM disintegration. 
Note that the resistance to loop formation, (or the rate of increase) in the NBCRMs, varied depending on the particular sample, such that it is possible to distinguish samples with inherently superior resistance to loop formation. However, there was a progressive increase in surface disintegration as the mechanical abrasion increased in the nonwoven BRMs (Table 2). It is therefore apparent, that whilst nonwoven BRMs were more susceptible to loop formation than the woven fabric (Sample D), their polymer composition, methods of manufacture and composite structure can potentially be engineered to influence overall resistance to mechanical disintegration.

Table 2: Mean number of loops per $\mathrm{cm}^{-2}$ on the surface of NBCRMs with increasing abrasion (pill box rotations).

\begin{tabular}{|l|l|r|r|r|r|r|r|}
\hline & & \multicolumn{6}{|c|}{ Pilling box rotations (n) } \\
\hline $\begin{array}{l}\text { Sample } \\
\text { Membrane }\end{array}$ & Front $(\boldsymbol{f}) /$ Back $(\boldsymbol{b})$ & $\mathbf{0}$ & $\mathbf{5 0}$ & $\mathbf{1 0 0}$ & $\mathbf{2 5 0}$ & $\mathbf{5 0 0}$ & $\mathbf{1 0 0 0}$ \\
\hline $\mathbf{A}$ & $\mathbf{A}_{(\mathbf{f})}$ & 5.27 & 9.80 & 12.73 & 19.43 & 29.57 & 51.43 \\
\cline { 2 - 8 } & $\mathbf{A}_{(\mathbf{b})}$ & 1.20 & 7.63 & 12.57 & 22.83 & 31.90 & 49.23 \\
\hline $\mathbf{B}$ & $\mathbf{B}_{(\mathbf{f})}$ & 1.27 & 2.83 & 7.90 & 16.90 & 26.57 & 52.73 \\
\cline { 2 - 8 } & $\mathbf{B}_{(\mathbf{b})}$ & 0.23 & 6.23 & 12.00 & 20.57 & 26.83 & 53.57 \\
\hline $\mathbf{C}$ & $\mathbf{C}_{(\mathbf{f})}$ & 0.03 & 0.07 & 0.07 & 0.17 & 0.07 & 0.43 \\
\cline { 2 - 8 } & $\mathbf{C}_{(\mathbf{b})}$ & 24.33 & 31.53 & 39.77 & 43.80 & 60.4 & 87.17 \\
\hline D & $\mathbf{D}_{(\mathbf{f})}$ & 0 & 0 & 0 & 0 & 0 & 0 \\
\hline & $\mathbf{D}_{(\mathbf{b})}$ & 0 & 0 & 0 & 0 & 0 & 0 \\
\hline
\end{tabular}

The degree of loop formation also varied in some samples (Table 2), on the face and back, which is likely to reflect differences in the structural architecture of the respective surfaces. It is not uncommon for textiles and nonwovens to exhibit differential abrasion resistance, face and back, and in the present samples, the composite nature of the nonwoven structures, i.e. multi-layer, means fabric specifications may not be identical on both sides. Interestingly, there was a notable difference of the face and back performance of Specimen $\mathrm{C}$ (compared to the other BRMs at the same number of pilling box rotations, which is due to greater structural integrity and resistance to filament displacement within the face surface. Specimen $\mathrm{C}$ was sealed on the front (Table 1). Sealing on the back would be likely to partly compromise its functionality, which accounts for the differences in performance recorded. 
From the test method (Figures 11-13), it was evident that Specimen A had the most loop formation per centimetre in less than 50 rotations when the front surface (where bats will predominantly be in contact with when roosting in the roof void) is considered. It was also observed to develop 50 loops $\mathrm{cm}^{-2}$ after 1000 rotations. Comparatively, this makes Specimen A (Figure 11) easily susceptible to loop formation increasing the likelihood of bat entanglement. In contrast, to produce just 2 loops $/ \mathrm{cm}^{2}$ on the front side of Specimen C (Figure 13) >5000 rotations would be required, highlighting a marked difference in the inherent resistance to loop formation between the BRMs.

It must however be noted that in contrast to standard building design configuration, where bats find themselves roosting between the roof tiles and at the back of the membrane, then Specimen C (Figure 13) becomes the most susceptible to loop formation and potentially bat entanglement. Specimen B (Figure 12) has comparable loop formation regardless of the side considered however, for the same number of rotations, loop formation on the back was marginally higher than that of the front. This is further explained by considering the overlapping of the error bars of the data for the front in comparison to that of the back and vice versa, which implies that the data is not significantly different. In addition, confirming that the loop formation at the front is similar to that which was formed at the back. The implication of the overlap is evident in Specimen A (50 and 1000 rotations).

It should be noted that loop formation appears to be recorded after 'No. of Rotations in Pilling Tester' is 0 (Figures $11-13$ ) however this is due to the nature of the spunbond fabric structure, where surface filaments project as loops at only certain points across the surface.

Specimen D did not show any loop formation on any of the samples, at either side of the nPRM regardless of the number of rotations applied (Table 2) due to the filaments being woven and sealed behind aluminium. 


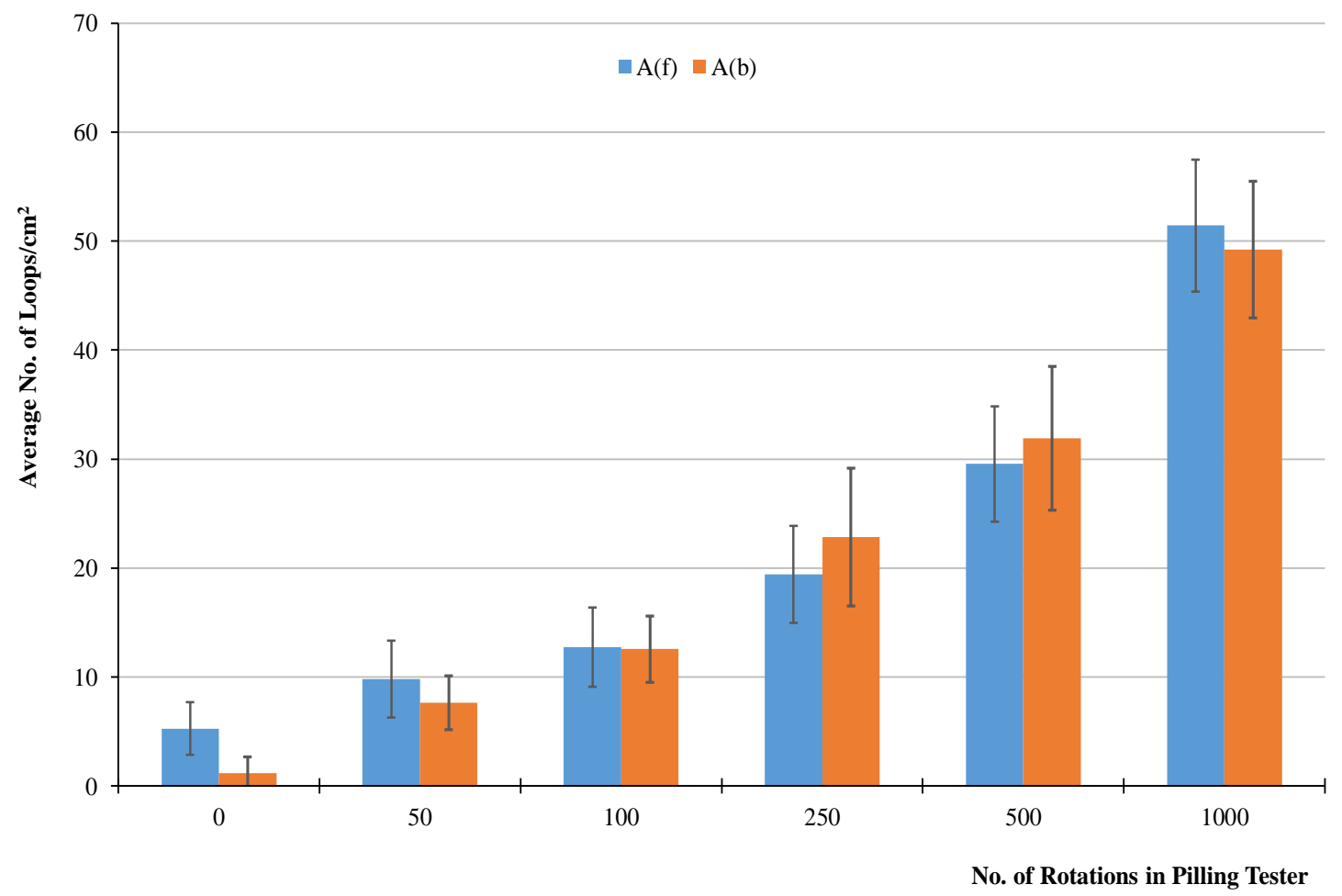

Figure 11. Average loop formation per $\mathrm{cm}^{2}$ developed after a known number of rotations of Specimen A within the Pilling box tester

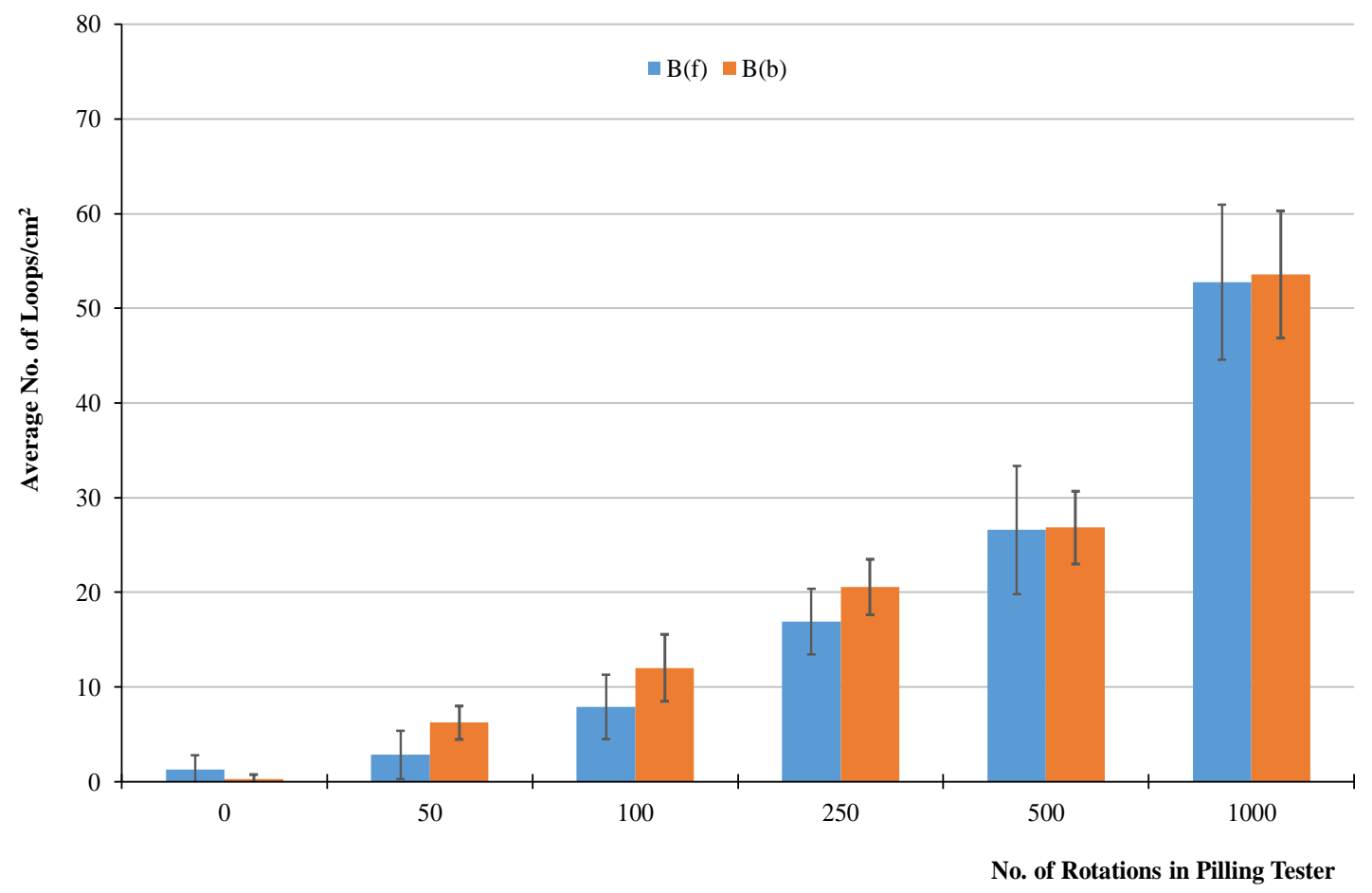

Figure 12. Average loop formation per $\mathrm{cm}^{2}$ developed after a known number of rotations of Specimen B within the Pilling Box tester 


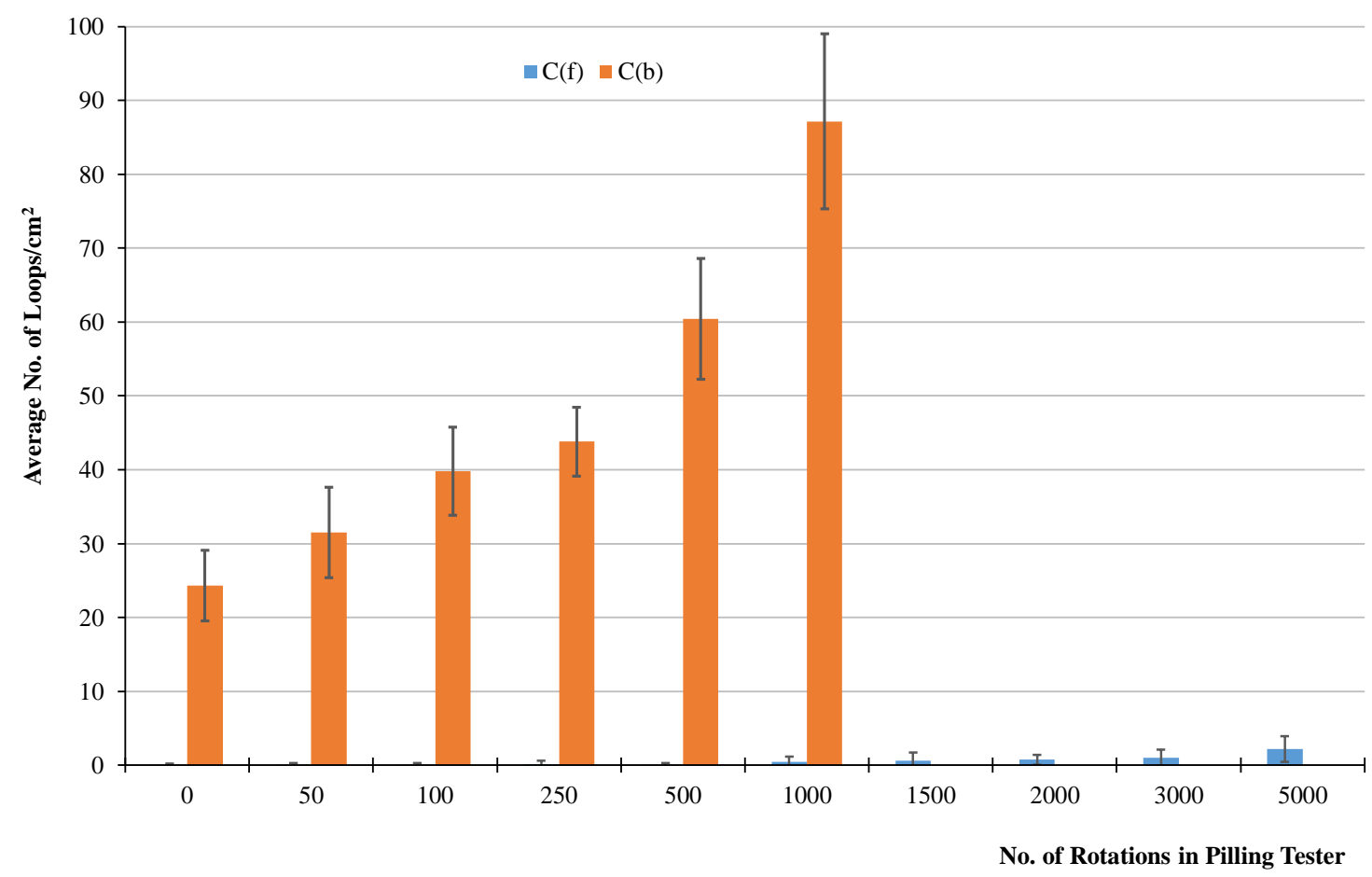

Figure 13. Average loop formation per $\mathrm{cm}^{2}$ developed after a known number of rotations of Specimen $\mathrm{C}$ within the Pilling Box tester

It is informative to consider these results in the light of the field study data obtained for the samples exposed to live bats at the Isle of Wight bat hospital. Firstly, it is evident from Figure 14 that the mode of damage, i.e. dislodgement of continuous filaments and 'fluffing' of the fabric surface evident in the bat aviary-retrieved samples is replicated in the pilling-box test method reported herein.

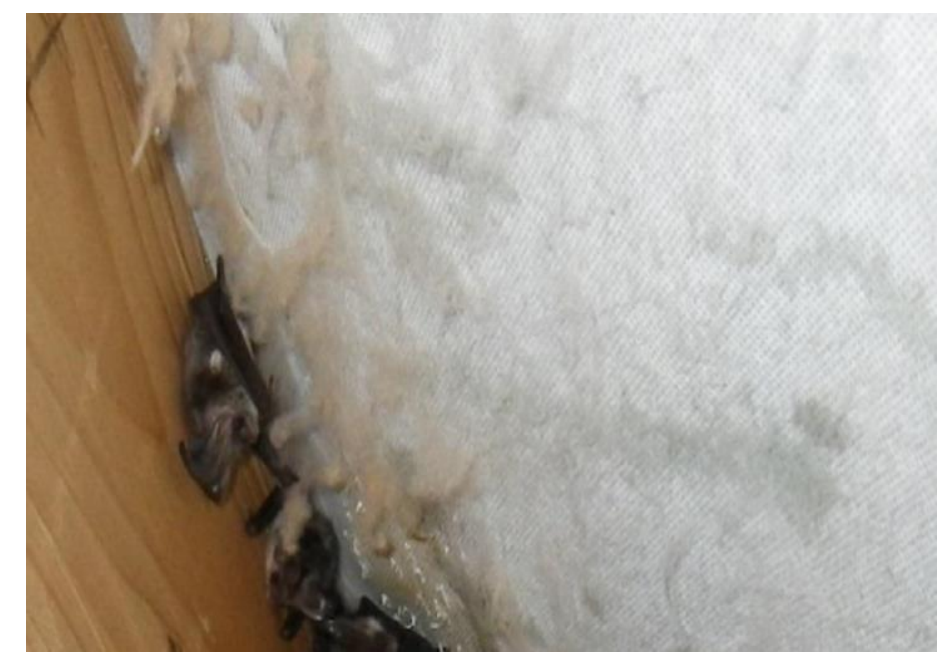

Figure 14. 'Fluffing' of a BRM surface four months after being fitted in a bat roost (Sample B)

When the mean loop formation data for the samples subjected to the new test method was compared with that retrieved from the Isle of Wight bat hospital field study, good agreement 
was observed (Figures 11-13). Given that the measured degree of loop formation from the aviary was the result of four months bat exposure, it was possible to link the degree of surface loop formation observed in the laboratory tests with that observed in the field. An extrapolation was then performed based on a polynomial curve to estimate the possible values of loop formation above the $\mathrm{n}_{\max }=1000$ pilling box rotations studied in these experiments.

The mean number of filament loops $/ \mathrm{cm}^{2}$ recorded from the aviary study were recorded as a horizontal line, intercepting the trend-line. The corresponding number of rotations within the laboratory test were extrapolated from the graphs.

Clearly, this approach does not take account of a number of important factors such as the number of bats using the roost (which will not be known in real life scenarios) or the area of the NBCRMs within the roof void, but it is useful as an initial insight. Correlation curves were produced linking the experimental data from the field and from the laboratory. For each of the specimens (A, B and C) tested, the average result was plotted with the sample error range on each side of the surface considered, which visually represents the variability of the data collated from the experiments (Figures 11-13). In the figures, the error bars represent standard error on the mean (SE) based on the sample data

To investigate the effect of the bats in the aviaries, only the effects of the loops $/ \mathrm{cm}^{2}$ at the front (as would be installed in a roof) of the membranes was compared to data from the pilling box test. The lack of loop formation in the pilling box test for Specimen D, was also evident in the aviaries at the Isle of Wight (IoW) bat hospital. This specimen was capable of resisting the formation of any loose filaments after four months installed in the aviaries. The other three BRM specimens, which were equally evaluated in the lab (figure 11-13) were also investigated in the Serotine and Pipistrelle aviary at the IoW bat hospital to ensure the pilling test results could be validated. Four months after installation of the BRMs in the aviaries, the number of loops observed on the surface of specimen was measured (see Figure 9), as illustrated in Figures $15-17$. The observed loop formation on samples was equivalent to 1000 rotations in the pilling box for two of the samples (A and B). The results from the aviaries at the IoW bat hospital demonstrated the same patterns of BRM disintegration and loop formation (Figure 15-17). This can be expected to vary as the duration of exposure to bat activity decreases or increases, or the number of bats vary in the aviaries. 


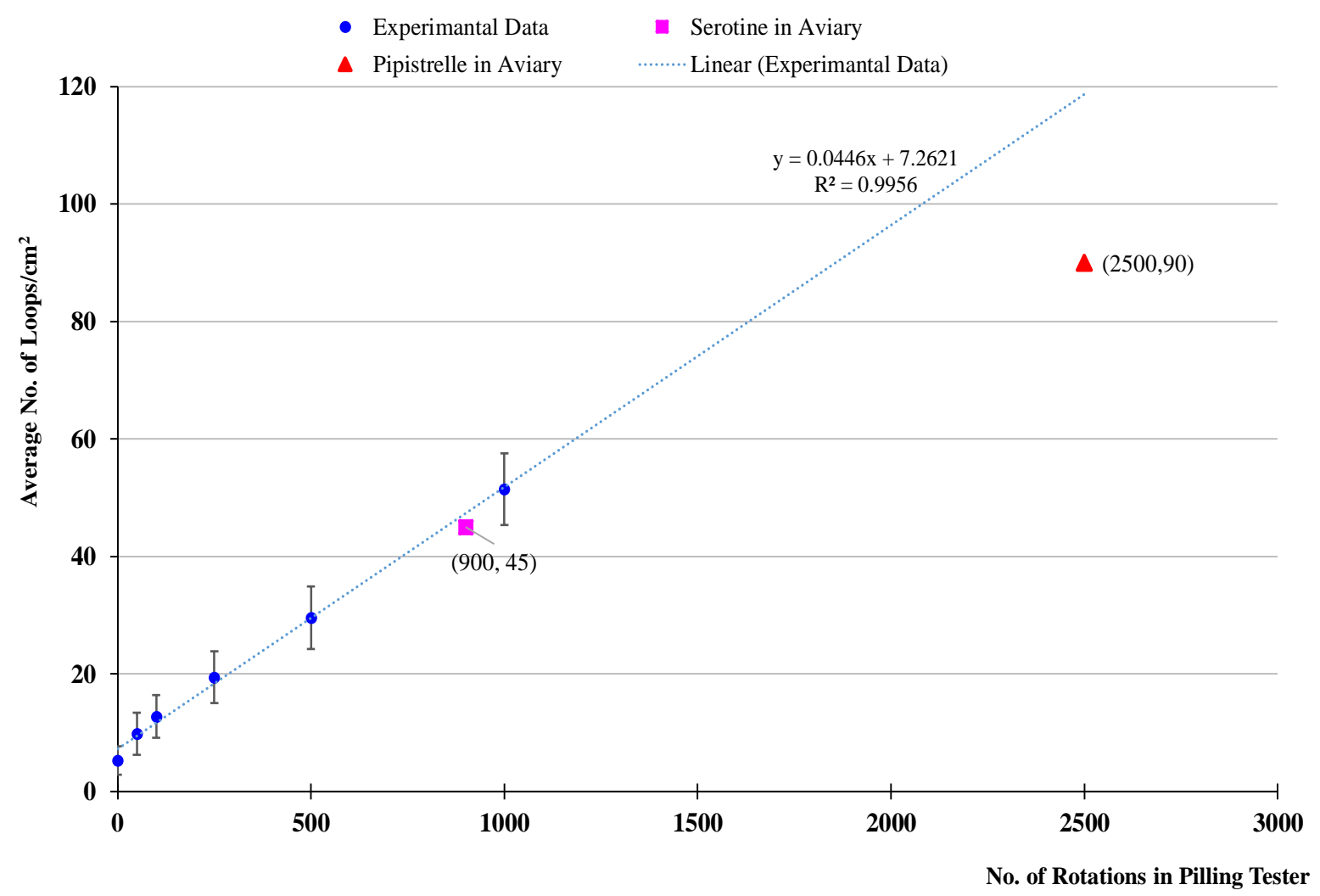

Figure 15. Mean loop formation on the BRMs in the bat aviary after 4 months vs. mean loop formation in the laboratory pilling box test (number of rotations up to 1000), including extrapolated projection. Specimen A (front)

From Figure 15, it is observed that after four months in the bat aviaries at IoW, approximately 45 loops $/ \mathrm{cm}^{2}$ were formed on the front surface of Specimen A by the Serotine, equating to 900 rotations in the pilling box test. There were 90 loops $/ \mathrm{cm}^{2}$ formed within the Pipistrelle aviary which based on the extrapolated trendline, equates to ca. 2500 rotations. 


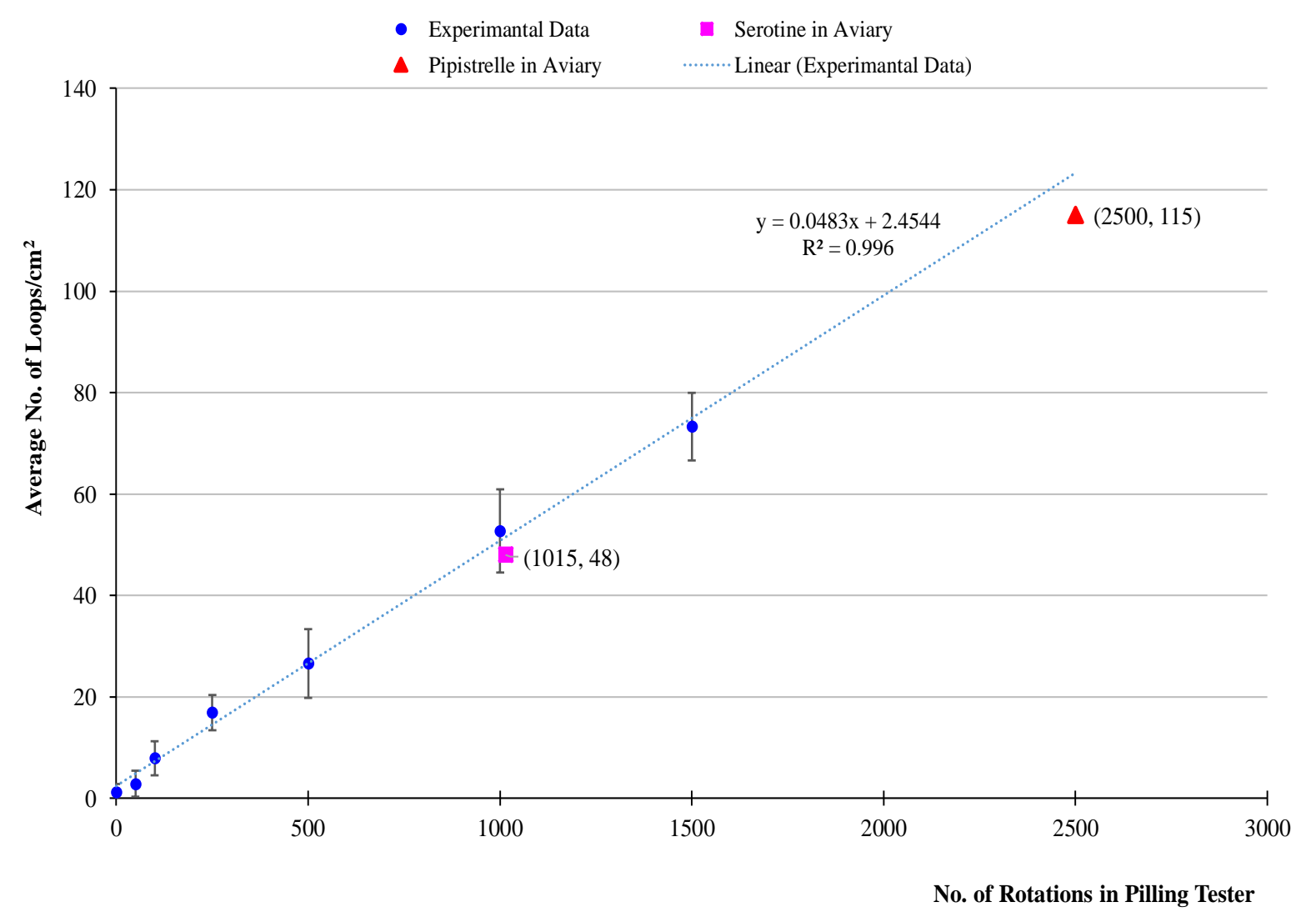

Figure 16. Mean loop formation of BRMs in the bat aviary after 4 months vs. mean loop formation in the laboratory pilling box test (number of rotations up to 1000), including extrapolated projection. Specimen B (front)

The loop formation on the surface of Specimen B (Figure 16) within the Serotine aviary was similar to that of Specimen A, with 48 loops $/ \mathrm{cm}^{2}$ formed, which equates to 1015 rotations. In the Pipistrelle aviary, after the same period (as in Specimen A) it was 2500 rotations. Mean of 115 loops $/ \mathrm{cm}^{2}$ were observed on Specimen B. 


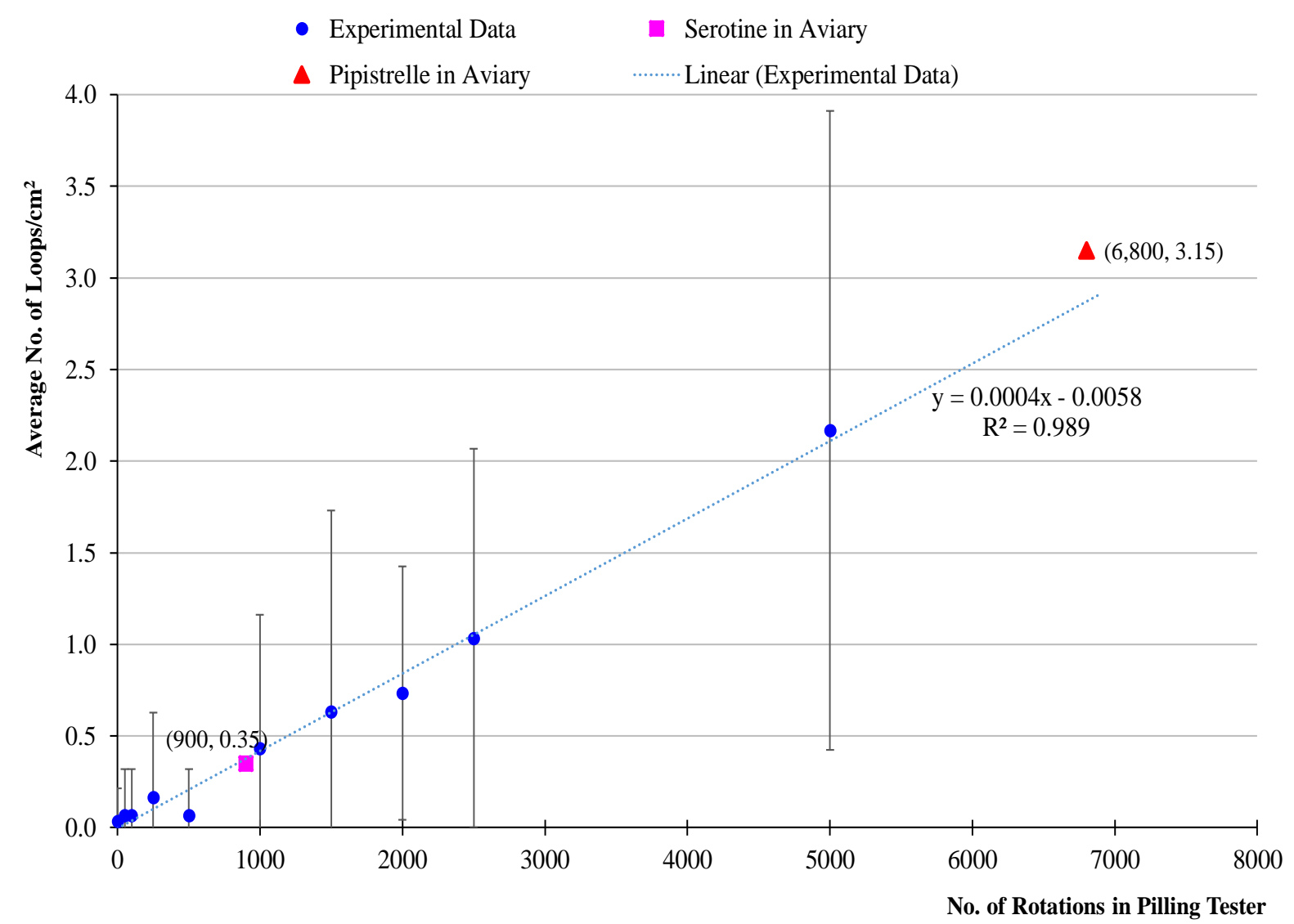

Figure 17. Mean loop formation of BRMs in the bat aviary after 4 months vs. mean loop formation in the laboratory pilling box test (number of rotations up to 1000), including extrapolated projection. Specimen C (front)

As in the case of Specimens A and B, after 4 months the loop formation on Specimen C (Figure 17) was 0.35 loops $/ \mathrm{cm}^{2}$ within the Serotine aviary, equivalent to 900 rotations. Within the Pipistrelle aviary, approximately 3.15 loops $/ \mathrm{cm}^{2}$ were observed which equates to over 6800 rotations. Comparatively, Specimen C exhibited substantially higher resistance to loop formation for the surface tested, and therefore a material that exbibits this level of resistance to loop formation on both surfaces would be considered the most suitable BRM for applications in roof voids where bats roost.

The results from the IoW field study, as illustrated in Figures 15-17, confirm the findings from the laboratory pilling test and suggests that the new test methodology can be used to represent the probable degree of damage and risk to a colony when bats crawl across the surface of a NBCRMs. The method is also capable of distinguishing between NBCRMs in terms of their resistance to loop formation, confirming differences observed in the field. 


\section{Conclusions}

The impact and attributes of four types of roofing underlays have been investigated using a newly developed laboratory test method, informed by NBCRM testing in the laboratory and real-life bat interactions.

A modified pilling box test method was found to mimic the surface disintegration of BRMs observed in field studies with live bats at the IoW bat hospital, providing a basis for an effective test method that is capable of distinguishing between the performance of roofing membranes to be used where they may come into contact with bats. Additionally, it was confirmed that the primary effect that leads to 'fluffing' on the surface of underlays is the 'plucking' and dislodgement of surface filaments from spunbond nonwoven BRMs by bat claws, leading to the formation of projecting loops on the surface.

Increasing the degree of bonding in spunbond nonwoven BRMs or use of after-treatments or finishing techniques such as coatings, adhesives or lamination to reduce the mobility and potential for surface filament dislodgement, will reduce the rate at which loops are formed on the BRM surface. In contrast, the woven nPRM sample was found to be highly resistant to loop formation and could therefore be expected to present a lower risk of entangling bats moving across its surface. However, while it would fall-short in respect of its functionality as a vapour permeable roofing membrane it would comply with modern building standards for use in some contexts in thatched buildings.

In summary, to adhere to protected species legislation and avoid harming bats, there is a need for a new generation of spunbond nonwoven NBCRMs with reduced propensity for fluffing through dislodgement of surface filaments. Testing of NBCRMs using the new laboratory pilling box methodology outlined in this paper, should yield a zero rate of change in the average number of loops $/ \mathrm{cm}^{2}$ as the number of rotations increases to at least 1000 rotations. Although this figure cannot be equated to a number of bats in a roost or a defined temporal period, it defines a threshold for substantially increased surface integrity in the NBCRM product.

\section{Acknowledgement}

The authors gratefully acknowledge the assistance provided by Michael Brookes in the testing laboratory of the School of Design, University of Leeds. 


\section{References}

Albrecht, W., (2003). Fibrous material. In: W. Albrecht, F.Hilmar \& W.Kittelmann, eds. Nonwoven fabrics: Raw materials, applications, characteristics and testing processes. Wiley$\mathrm{VCH}, \mathrm{pp} 15-85$

Bat Conservation Trust (BCT), 2019 -Roosts in buildings https://www.bats.org.uk/about-bats/where-do-bats-live/bat-roosts/roosts-in-buildings [Accessed 20 January 2019].

Bhat, G., (2007). Polymer-laid web formation. In: S. Russell, ed. Handbook of nonwovens. Cambridge: Woodhead Publishing Ltd., pp.143-200.

Briggs, P. (2004) Effect of barn conversion on bat roost sites in Hertfordshire, England Mammalia 68(4):353-364

BSI, (1986). BS 5811:1986. Method for determination of the resistance to pilling and change of appearance of fabrics. British Standards Institution. Available through: British Standards Online <https://bsol.bsigroup.com/> [Accessed 1 June 2014].

BSI, (1996). BS EN 863:1996 Protective clothing. Mechanical properties. Test method: puncture resistance. British Standards Institution. Available through: British Standards Online $<$ https://bsol.bsigroup.com/> [Accessed 2 June 2014].

BSI, (2000a). BS 747:2000 Reinforced bitumen sheets for roofing. Specification, GBM48 (Construction In General). British Standards Institute. British Standards Institution. Available through: British Standards Online <https://bsol.bsigroup.com/> [Accessed 4 May 2016].

BSI (2000). BS EN 12310-1:2000 Flexible sheets for waterproofing. Determination of resistance to tearing (nail shank). Bitumen sheets for roof waterproofing. British Standards Institution. Available through: British Standards Online <https://bsol.bsigroup.com/> [Accessed 5 May 2014].

BSI, (2001). BS EN ISO12945-1:2001 Textiles. Determination of fabric propensity to surface fuzzing and to pilling. Pilling box method. British Standards Institution. Available through: British Standards Online <https://bsol.bsigroup.com/> [Accessed 12 April 2014].

BSI, (2003). BS 5534:2003+A1:2010 Code of practice for slating and tiling (including shingles). British Standards Institution. Available through: British Standards Online $<$ https://bsol.bsigroup.com/> [Accessed 20 November 2014].

BSI, (2008). BS8479:2008 Textiles. Method for determination of the propensity of fabrics to snagging. Rotating chamber method. British Standards Institution. Available through: British Standards Online <https://bsol.bsigroup.com/> [Accessed 23 October 2014].

BSI, (2011). BS 5250:2011 Code of practice for control of condensation in buildings. British Standards Institution. Available through: British Standards Online $<$ https://bsol.bsigroup.com/> [Accessed 22 November 2015]. 
BSI, (2011b). BS EN ISO139:2005+A1:2011 Textiles. Standard atmospheres for conditioning and testing. British Standards Institution. Available through: British Standards Online $<$ https://bsol.bsigroup.com/> [Accessed 20 November 2015].

Conservation of Habitats and Species Regulations, 2017. http://www.legislation.gov.uk/uksi/2017/1012/pdfs/uksi_20171012_en.pdf. [Accessed 20 January 2019].

DuPont, (2011) - Your home deserves better protection. [Product Brochure Online]. Available at: $\quad$ http://www.dupont.co.uk/content/dam/assets/products-and-services/constructionmaterials/tyvek-building-envelope/Documentation/Literature/DuPont-Tyvek-ProductBrochure.pdf [Accessed 23 November 2016].

EDANA, (2017). European Nonwovens Production and Deliveries. Nonwoven Statistics-Facts and Figures.

[Online] Available at: http://www.edana.org/discover-nonwovens/facts-and-figures [Accessed 20 June 2012].

Entwistle ,. C., Racey P. A. and Speakman J. R.. Roost Selection by the Brown Long-Eared Bat Plecotus auratus. Journal of Applied Ecology Vol. 34, No. 2 (Apr., 1997), pp. 399-408 (10 pages) Published by: British Ecological Society.

EUROBATS- The Agreement on the Conservation of Populations of European Bats https://www.eurobats.org/ [Assessed 15 March 2020]

EUROBATS- Working Group

https://www.eurobats.org/activities/intersessional_working_groups [Assessed 15 March 2020]

Goss, R., (2007). Goss's roofing ready reckoner : metric dimensions for timber roofs of any span and pitch. 4th Edition. Oxford; Blackwell Publishing.

Knauf (2019). Pitched roofs - ceiling level Insulation at ceiling level design https://www.knaufinsulation.co.uk/sites/ki_gb/files/images/applications/2.1-Pitched-RoofsCeiling-Level.pdf [Accessed 20 January 2019].

Kunz, T.H. \& Reynolds, D.S., (2003). Bat colonies in buildings. US Geological Survey Information and Technology Report USGS/BRDT/ITR-2003-003. Washington: US Geological Survey.

Kamath, M.G., Dahiya, A. \& Hegde, R.R., (2004). Thermal bonding of nonwoven fabrics. [Online]. Available at: http://www.engr.utk.edu/mse/Textiles/Thermal\%20Bonding.htm [Accessed 23 November 2014].

Loomans, M.G.L.C., 1998.The measurement and simulation of indoor airflow-PhD ThesisTechnical University, Eindhoven, ISBN 90-6814-085-X, pp. 1-6, 29

Marnell F, Presetnik P. Protection of overground roosts for bats (particularly roosts in buildings of cultural heritage importance). Bonn: Eurobats; 2010. 
Massenaux, G., (2003). Introduction to nonwovens. In: W.Albrecht, H. Fuchs \& W.Kittelmann, eds. Nonwoven Fabrics: Raw Materials, Applications, Characteristics and Testing Processes. Verlag: Wiley-VCH.

Sanders, C.H. 2002. Improved thermal and moisture performance of pitched roofs. PiI (Partners in Innovation) Project. Progress report 1, number 16311. pp. 1-5

Santamouris, M. et al., 1998. Natural ventilation in buildings: a design handbook. LondonUK, James and James (Science Publisher) Ltd. pp. 1-4

Schofield, H., (2008). The lesser horseshoe bat: conservation handbook, Ledbury: Vincent Wildlife Trust.

Schofield, H. \& Mitchell-Jones, A.J., (2010). Bats of Britain and Ireland, $4^{\text {th }}$ edition. Ledbury: Vincent Wildlife Trust.

Stirling, C., (2009). Building technologies: Breather membranes. National Building Specification.

Wildlife and Countryside Act, 1981

https://www.legislation.gov.uk/ukpga/1981/69/pdfs/ukpga_19810069_en.pdf [Accessed 10 February 2019].

Wardhaugh, A.A., (1992). Bats and their roosts in Cleveland and North East Yorkshire. Naturalist, vol.117, pp.99-108.

Waring, S. D., Essah, E., Gunnell, K. \& Bonser, R., (2013). Double jeopardy: the potential for problems when bats interact with breathable roofing membranes in the United Kingdom. Architecture \& Environment, vol.1(1), pp.1-13.

Waring Stacey (2014), The Interactions between Bats and Breathable Roofing Membranes. $\mathrm{PhD}$ thesis, University of reading

Waring, Stacey D. and Essah, Emmanuel A. (2016). Morphometric analysis of body and claw dimensions of building dwelling UK bat species: to aid knowledge of bat interactions with roosting surfaces. Acta Chiropterologica, 18(2): 527-534, doi: 10.3161/15081109ACC2016.18.2.019

Wilson, A., (2007). Development of the nonwovens industry. In: S. Russell, ed. Handbook of nonwovens. Cambridge: Woodhead Publishing Ltd., pp.1-15.

Williams, C, Gunnell, K, Murphy, B (2013). Design for Biodiversity: A Technical Guide for New and Existing Buildings. RIBA Publishing.

https://www.bats.org.uk/resources/guidance-for-professionals/designing-for-biodiversity-atechnical-guide-for-new-and-existing-buildings [Accessed 25 March 2020].

Witteveen, C.R. \& Lucas, L.L., (2000). To tear or not to tear. [Online]. Available at: http://docserver.nrca.net/pdfs/technical/7305.pdf [Accessed 23 November 2014]. 